\title{
Reduced expression of bone morphogenetic protein receptor IA in pancreatic cancer is associated with a poor prognosis
}

\author{
P W Voorneveld ${ }^{1}$, V Stache ${ }^{1,2}$, R J Jacobs ${ }^{1}$, E Smolders ${ }^{1}$, A I Sitters ${ }^{1}$, A Liesker ${ }^{1}, \mathrm{~K} \mathrm{~S} \mathrm{Korkmaz}{ }^{1}, \mathrm{~S} \mathrm{M} \mathrm{Lam}^{3}$, \\ N F C C De Miranda ${ }^{4,5}$, H Morreau ${ }^{5}$, L L Kodach ${ }^{1}$ and J C H Hardwick ${ }^{*, 1}$ \\ ${ }^{1}$ Department of Gastroenterology and Hepatology, Leiden University Medical Center, Leiden, The Netherlands; ${ }^{2}$ Max Delbrück \\ Center for Molecular Medicine, Berlin, Germany; ${ }^{3}$ Department of Molecular Cell Biology, Leiden University Medical Center, \\ Leiden, The Netherlands; ${ }^{4}$ Division of Clinical Immunology, Karolinska Institute, Stockholm, Sweden and ${ }^{5}$ Department of \\ Pathology, Leiden University Medical Center, Leiden, The Netherlands
}

Background: The expression of SMAD4, the central component of the transforming growth factor- $\beta$ (TGF- $\beta$ ) and bone morphogenetic protein (BMP) signalling pathways, is lost in 50\% of pancreatic cancers and is associated with a poor survival. Although the TGF- $\beta$ pathway has been extensively studied and characterised in pancreatic cancer, there is very limited data on BMP signalling, a well-known tumour-suppressor pathway. BMP signalling can be lost not only at the level of SMAD4 but also at the level of BMP receptors (BMPRs), as has been described in colorectal cancer.

Methods: We performed immunohistochemical analysis of the expression levels of BMP signalling components in pancreatic cancer and correlated these with survival. We also manipulated the activity of BMP signalling in vitro.

Results: Reduced expression of BMPRIA is associated with a significantly worse survival, primarily in a subset of SMAD4-positive cancers. In vitro inactivation of SMAD4-dependent BMP signalling increases proliferation and invasion of pancreatic cancer cells, whereas inactivation of BMP signalling in SMAD4-negative cells does not change the proliferation and invasion or leads to an opposite effect.

Conclusion: Our data suggest that BMPRIA expression is a good prognostic marker and that the BMP pathway is a potential target for future therapeutic interventions in pancreatic cancer.

Pancreatic cancer is a particularly lethal disease with a 5-year survival of only $4 \%$ (Jemal et al, 2011). The poor prognosis is partly because early stage pancreatic cancers typically do not lead to clinical symptoms and partly because of the poor response to chemotherapy (Vincent et al, 2011). At the time of diagnosis, the tumour has usually invaded surrounding organs or metastasised, resulting in $80-85 \%$ of the tumours being inoperable. There is thus an urgent need for better understanding of the molecular mechanisms involved in order to develop alternative treatment options and better predict prognosis.
Mutations in SMAD4, also known as depleted in pancreatic cancer locus 4 (DPC4), occur in $>50 \%$ of pancreatic cancers (Hahn et al, 1996; Rozenblum et al, 1997; Tascilar et al, 2001). The inactivation of SMAD4 occurs relatively late in the adenomato-carcinoma sequence with loss of expression first seen at the Pan-IN3 stage and being associated with a poorer prognosis (Wilentz et al, 2000; Tascilar et al, 2001). The relevance of SMAD4 loss has been shown by restoration of SMAD4 in SMAD4-depleted pancreatic cancer cell lines, which leads to reduced growth (Duda et al, 2003). 
SMAD4 is a central and critical component of both the transforming growth factor- $\beta$ (TGF- $\beta$ ) and the bone morphogenetic protein (BMP) signalling pathways. TGF- $\beta$ signalling can be tumour suppressive in normal epithelial cells and tumour promoting in the later stages of cancer with different functional effects dependent on the SMAD4 status (Massague et al, 2000; Jazag et al, 2005; Schniewind et al, 2007; Romero et al, 2008). TGF- $\beta$ receptor II mutations are found in $4-7 \%$ of pancreatic cancers further supporting the importance of TGF- $\beta$ signalling in pancreatic cancer tumourigenesis (Massague, 1998; Hansel et al, 2003).

The role of the BMP signalling pathway in pancreatic cancer is much less clear. BMP ligands bind to a complex of transmembrane serine threonine kinase receptors consisting of type I (BMPRIA or BMPRIB) and type II (BMPRII) receptors. On binding of the BMPs to the receptor complex, the type I receptor (BMPRIA or BMPRIB) is phosphorylated by BMPRII, which leads to downstream phosphorylation and activation of the BMP-specific SMADs, SMAD1, 5 and 8. Phosphorylated SMAD1, 5 or 8 then complexes with the co-SMAD, SMAD4. SMAD4 is crucial for the modulation of gene transcription as it facilitates the translocation of pSMAD $1 / 5 / 8$ to the nucleus (Massague, 1998). Germline mutations of BMPRIA and SMAD4 are found in juvenile polyposis, a rare autosomal dominant polyposis syndrome with a high lifetime risk of colorectal cancer (Howe et al, 1998, 2001), and BMPRII expression loss is found in colorectal cancers with microsatellite instability (Kodach et al, 2008b). This further suggests that the BMP pathway is important in maintaining epithelial cell homeostasis. However, little is known about the expression levels of the different BMP signalling components in pancreatic cancer.

Therefore, we set out to assess expression levels of the BMP receptors (BMPRs) in pancreatic cancer tissue and relate this to patient survival data. We then tested the relevance of our findings by investigating the influence of BMPR expression on pancreatic cancer cell proliferation and invasion in vitro.

\section{MATERIALS AND METHODS}

Immunohistochemistry. Pancreatic ductal adenocarcinoma (PDAC) tissue was stained according to previously described methods (Kodach et al, 2008a). A list of antibodies with the concentrations used is provided in the Supplementary Methods.

Tissue microarray. A tissue microarray (TMA) containing PDAC tissue was constructed from formalin-fixed, paraffin-embedded tissue from 41 patients with PDAC who underwent surgery in the Leiden University Medical Center. All cases were reported by a single GI pathologist (HM). Survival data of the 41 patients with PDAC included in the TMA were collected. The mean survival time from the date of surgery was $373 \pm$ s.d. 268 days (range 37-1367 days). All patients died within the follow-up period.

TMA analysis. Analysis was performed in a blinded manner by two investigators independently. SMAD4 expression was scored according to previously described methods (Kodach et al, 2008a). Immunohistochemical staining for the receptors was scored according to a scoring system we have developed and validated for colorectal cancer, as shown in Supplementary Methods. Further division of expression was made into negative (scores 0 and 1) and positive (scores 2 and 3). The final score of agreement for all stainings was $\kappa>0.7$.

Immunoblotting. Western blot analysis was performed according to previously described methods (Kodach et al, 2008b). A list of antibodies with the concentrations used is provided in the Supplementary Methods.
PCR. PCR was performed according to previously described methods (Kodach et al, 2008b). Primer sequences and protocols can be provided on request. GAPDH was used as a loading control.

Cell lines. PANC-1, MIA PaCa-2 and Bx-PC3 human PDAC cell lines were obtained from the ATCC (Manassas, VA, USA) and were grown in Dulbecco's modified Eagle's medium $4.5 \mathrm{gl}^{-1}$ glucose and L-glutamine (Invitrogen, Breda, The Netherlands), supplemented with $50 \mathrm{U} \mathrm{ml}^{-1}$ penicillin and $50 \mu \mathrm{g} \mathrm{ml}^{-1}$ streptomycin and $10 \%$ foetal calf serum (Invitrogen). Cells were grown in monolayers at $37^{\circ} \mathrm{C}$ in a humidified atmosphere containing $5 \% \mathrm{CO}_{2}$.

Invasion assay. In all, $8 \mu \mathrm{m}$ pore size HTS FluoroBlok Cell Culture Inserts (BD Falcon, Breda, The Netherlands) were coated with $100 \mu \mathrm{l}$ of a 1:1 mix of serum-free media and Matrigel. Inserts were placed in 24-well plates (Corning Incorporated, Corning, NY, USA). Cells were labelled with $5 \mu \mathrm{m}$ CellTracker Green CMFDA (Invitrogen) according to the manufacturer's instructions after which they were detached using trypsin with 2 mм EDTA. Cells were transferred in medium containing $1 \%$ FCS to the upper well of a transwell invasion system. A volume of $600 \mu$ l of culture medium containing $10 \%$ FCS was used as an attractant and placed in the lower chamber. Fluorescence of the invaded cells at the lower side of the transwell was measured every $2 \mathrm{~h}$ using the BioTek Flx800 (BioTek, Winooski, VT, USA). Data were corrected for background fluorescence and migration start points were set to zero.

MTT assay. Cells were seeded in 96-wells plates. For viability measurement, 3-(4,5-dimethylthiazol-2-yl)-2,5-diphenyltetrazolium bromide (MTT) solution was added for $2 \mathrm{~h}$ at $37^{\circ} \mathrm{C}$ $\left(0.5 \mathrm{mg} \mathrm{ml}^{-1}\right)$ after which the absorbance of the samples at $562 \mathrm{~nm}$ was measured.

BMP ligand and BMP inhibitor. Stock solution of recombinant human BMP-2 (R\&D systems, Oxon, UK) was prepared in PBS and subsequently dissolved in culture medium for treatment $\left(100 \mathrm{ng} \mathrm{ml}^{-1}\right)$. Stock solutions of the BMPRIA inhibitor LDN193189 (AxonMedchem BV, Groningen, The Netherlands) were prepared in dimethyl sulfoxide and subsequently dissolved in culture medium for treatment.

shRNA against SMAD4. Lentiviral constructs expressing shRNAs targeting SMAD4 (TRCN0000040028) and a non-targeting control construct (SHC002) were obtained from the Sigma MISSION shRNA library (Sigma-Aldrich, St Louis, MO, USA). Production of lentiviruses by transfection into $293 \mathrm{~T}$ cells has been described earlier (Carlotti et al, 2004). Cells were selected using puromycin.

siRNA knockdown. For siRNA knockdown of BMPRIA, cells were transfected with either siRNA against BMPRIA (ID: s280) or scrambled siRNA (Invitrogen). Lipofectamine 2000 (Invitrogen) was used for all transfections according to the manufacturer's instructions.

Luciferase reporter assay. For quantitative measurement of BMP, reporter assays were used. Cells were transfected with BRE-luc constructs (kindly provided by $\mathrm{P}$ ten Dijke). Transfection with a pcDNA3.1 vector expressing Renilla luciferase was used as a transfection control. Luciferase activity was measured using a Dual-Luciferase Reporter Assay (Promega, Madison, WI, USA) according to the manufacturer's protocol. Lipofectamine 2000 (Invitrogen) was used for all transient transfections according to the manufacturer's instructions.

Statistical analysis. Statistical analyses were performed with Prism 5 for Windows (GraphPad Software, Inc., La Jolla, CA USA) using the Student's $t$-test and with PASW Statistics 18 for Windows (SPSS, Inc., IBM, NY, USA) using Kaplan-Meier analysis, Fisher's exact test, $\chi^{2}$ test, log-rank test and Cohen's kappa as appropriate. 


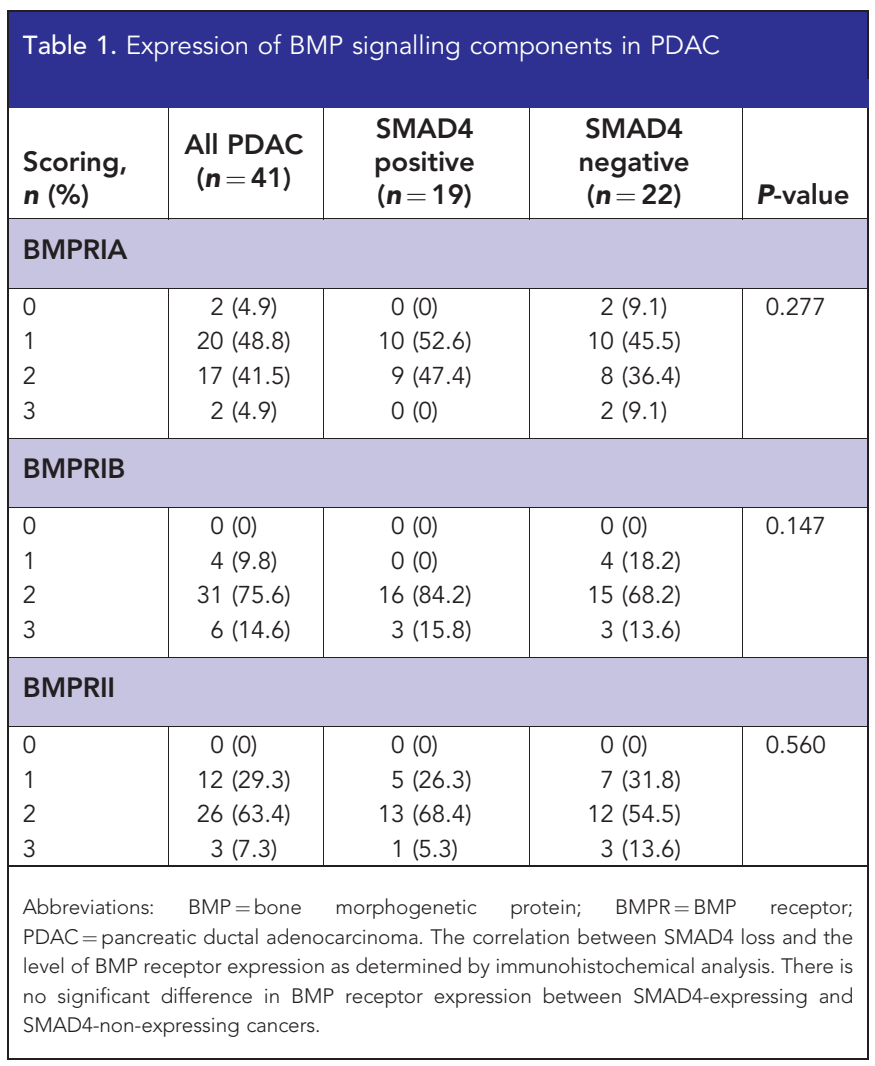

\section{RESULTS}

Expression of BMPRIA protein is frequently reduced in PDAC. In order to investigate the expression levels of the BMP signalling components, we selected the 41 cases of PDAC from our TMA and performed immunohistochemistry for SMAD4, BMPRIA, BMPRIB and BMPRII. Examples of the stainings can be found in Supplementary Figure 1. SMAD4 is lost in half (53.7\%) of the PDAC cases, which is in concordance with the literature (Tascilar et al, 2001). BMPRIA, BMPRIB and BMPRII expression is reduced in $53.7 \%, 9.8 \%$ and $29.3 \%$ of PDAC, respectively (Table 1). We then related the BMPR expression levels to the SMAD4 status and observed no correlation, thus SMAD4 and the BMPRs are lost independently in PDAC. Loss of SMAD4 expression has previously been shown to be associated with a poor prognosis and we could confirm this in our dataset $(P=0.04$; Figure $1 \mathrm{~A})$. Reduced BMPRIA expression is associated with poorer survival $(P=0.008$; Figure $1 \mathrm{~B})$. Interestingly, when stratifying for the SMAD4 status a significant difference can be observed within the SMAD4-positive group, but not within the SMAD4-negative group (Figure $1 \mathrm{C}$ and $\mathrm{D}$ ). This suggests that changes in BMPRIA expression only have major consequences when SMAD4 expression is still intact. SMAD4 is a central component of the BMP signalling pathway and when lost there is gross impairment of canonical BMP signalling. From this, it would be expected that reduction of BMPRIA expression in SMAD4-negative cells would have little additional impact on canonical BMP signalling, because it is already lost as a consequence of the SMAD4 loss. Reduced
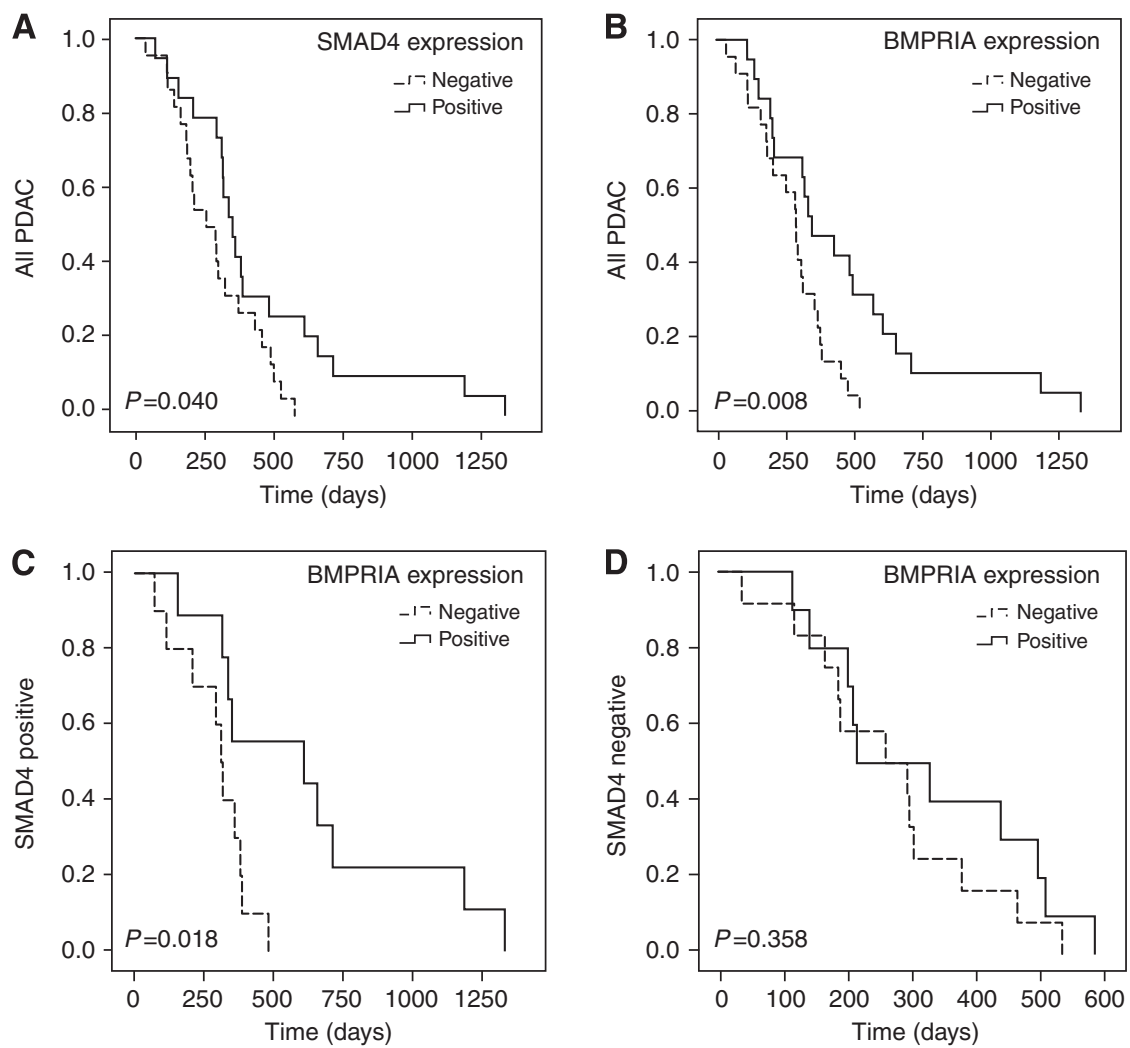

Figure 1. Kaplan-Meier graphs representing the survival of 41 patients after surgical resection of PDAC based on SMAD4 and BMPRIA expression in a TMA. (A) SMAD4 positive vs SMAD4 negative $(P=0.040)$. (B) BMPRIA positive vs BMPRIA negative $(P=0.008)$. (C) BMPRIA positive vs BMPRIA negative within SMAD4-positive PDAC $(P=0.018)$. (D) BMPRIA positive vs BMPRIA negative within SMAD4-negative PDAC $(P=0.358)$. $P$-values are based on log-rank tests. 
expression of BMPRIB or BMPRII does not lead to a difference in survival, even when stratifying for SMAD4 expression (Supplementary Figure 2).

BMPRIA reduction leads to an increase in proliferation and invasion. In order to investigate the functional role of the BMP pathway in PDAC in vitro, we first investigated the expression of BMPRIA and SMAD4 in three PDAC cell lines (PANC-1, MIA $\mathrm{PaCa}-2$ and $\mathrm{Bx}-\mathrm{PC} 3$ ). RT-PCR using primers specific for exon 13 of BMPRIA suggests that BMPRIA RNA is expressed in all three PDAC cell lines (Figure 2A). MIA PaCa-2 expresses lower levels of BMPRIA compared with PANC-1 and Bx-PC3 as shown by western blot analysis (Figure 2B). PANC-1 and MIA PaCa-2 both express SMAD4, whereas Bx-PC3 does not. The colorectal cancer cell lines HCT116 and SW480 were used as controls. HCT116 expresses SMAD4, but low levels of BMPRs and SW480 expresses no SMAD4 and high levels of BMPRs. In a luciferase reporter assay for BMP pathway signalling activity (BRE-luc), treatment of the cell lines with BMP-2 for $24 \mathrm{~h}$ leads to a significant increase in luciferase activity in PANC-1 and a less significant increase in MIA $\mathrm{PaCa}-2$, but no increase in Bx-PC3 (Figure 2C; Korchynskyi and Ten, 2002; Kodach et al, 2008b). We conclude that PANC-1 and MIA PaCa-2 have the ability to activate BMP signalling, whereas Bx-PC3 has not.

We knocked down BMPRIA expression using siRNA and subsequently performed viability/proliferation and matrigel invasion assays. From the human data shown in Figure $1 \mathrm{~B}-\mathrm{D}$, we would predict that knockdown of BMPRIA expression in the SMAD4-positive cell lines PANC-1 and MIA PaCa-2 will have functional effects, but knockdown of BMPRIA in the SMAD4negative cell line Bx-PC3 should have no functional effect because BMP signalling is already lost because of SMAD4 loss. Figure 2D shows the effect of BMPRIA knockdown after $48 \mathrm{~h}$ on cell viability/ proliferation. A significant increase in viability/proliferation can be seen in the SMAD4-positive cell lines after BMPRIA knockdown. SMAD4-negative Bx-PC3 cells do not show an effect, as expected. Next, we performed a matrigel invasion assay in which we knocked down BMPRIA and measured fluorescently labelled cells that have
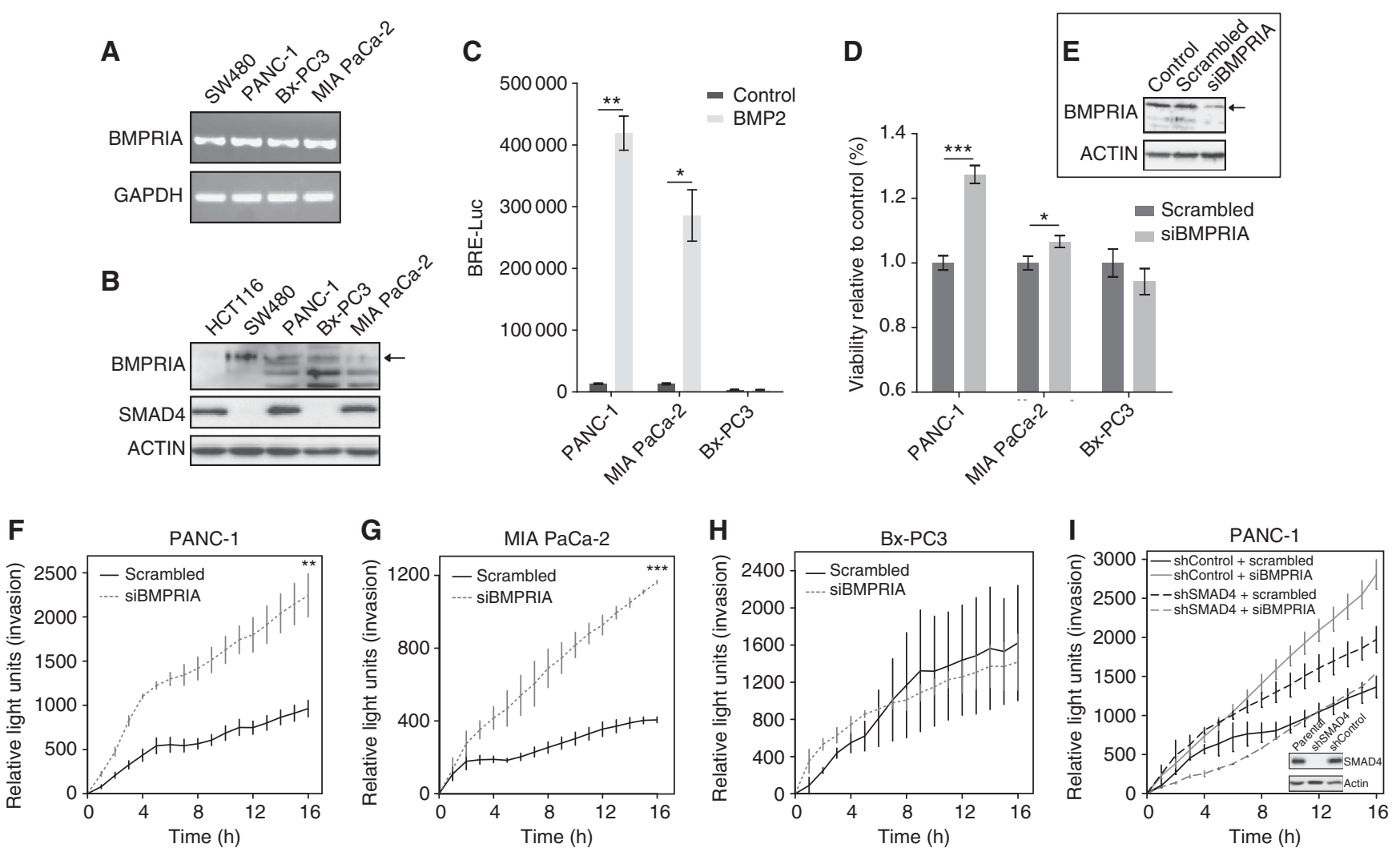

Figure 2. BMPRIA knockdown increases proliferation and invasion in SMAD4-positive PDAC cell line cells. (A) RT-PCR showing RNA expression of BMPRIA in the PDAC cell lines PANC-1, MIA PaCa-2 and Bx-PC3. GAPDH is used as a loading control. (B) Western blot analysis showing SMAD4 $(61 \mathrm{kD})$ and BMPRIA ( 66 kD) expression. The colorectal cancer cell lines HCT116 and SW480 were used as controls. Actin was used as a loading control. (C) The ability of BMP ligands to activate BMP signalling in PDAC cell lines PANC-1, MIA PaCa-2 and Bx-PC3. BMP signalling activation is shown by BRE-luciferase activity after treatment with $100 \mathrm{ng} \mathrm{ml}^{-1}$ BMP-2 dissolved in PBS for $24 \mathrm{~h}$. (D) The effect of BMPRIA knockdown for $48 \mathrm{~h}$ on viability/proliferation in PANC-1, MIA PaCa-2 and Bx-PC3. Transfection with siRNA against BMPRIA was used for BMPRIA knockdown. Transfection with scrambled siRNA was used as a control. (E) Western blot analysis showing BMPRIA knockdown ( $66 \mathrm{kD})$ using transfection of siRNA against BMPRIA in PANC-1. siRNA scrambled was used as a control. Actin was used as a loading control. (F-H) The effect of BMPRIA knockdown on invasion in PANC-1 (F), MIA PaCa-2 (G) and Bx-PC3 (H). Matrigel in Fluoblock filters were used in a transwell system. Cells were labelled with Celltracker and invasion through matrigel was calculated using fluorescent measurements in the bottom wells every hour. The measurements were corrected for background fluorescence and set to zero at starting point. Transfection with siRNA against BMPRIA was used for BMPRIA knockdown. Transfection with scrambled siRNA was used as a control. (I) SMAD4 was knocked down in PANC-1 cells using shRNA. The nontargeting control construct SHCOO2 was used to make a control cell line. Western blot analysis shows SMAD4 (61 kD) knockdown. Actin is used as a loading control. Subsequently BMPRIA was knocked down using siRNA. Scrambled siRNA was used as a control. Next, a matrigel invasion array was performed. (All experiments were performed in triplicate. Mean \pm s.e.m. is shown, ${ }^{\star} P<0.05,{ }^{\star \star} P<0.005,{ }^{\star \star \star} P<0.0005$ ). 
passed through the matrigel in a transwell system. In PANC-1 as well as the MIA PaCa-2 cells, an increase in invasion can be observed after BMPRIA knockdown. BMPRIA reduction in Bx-PC3 does not lead to a significant difference in invasion (Figure 2F-H).

The effects of the BMP pathway seem to be dependent on the SMAD4 status. To investigate the function of SMAD4 in PDAC cells, we made a cell line in which SMAD4 was stably knocked down by performing lentiviral transduction with shRNA against SMAD4 in SMAD4-positive PANC-1 cells, as well as a control cell line using a control construct. We then silenced BMPRIA and performed an invasion assay. Knockdown of SMAD4 leads to increased invasion (Figure 2I). The use of siBMPRIA in the shControl (SMAD4 positive) cells results in more invasion. We expected that silencing of BMPRIA in the shSMAD4 clone would not have any effect, but instead it lowers the invasion rate.

BMPRIA knockdown changes the expression of angiogenesis, mesenchymal, cancer stem cell and matrix modifier markers. To further elaborate the cell changes resulting from BMPRIA loss in SMAD4-positive PDAC cells, we knocked down BMPRIA in PANC-1 cells and measured the mRNA levels of a set of markers associated with angiogenesis, epithelial-to-mesenchymal transition (EMT), cancer stemness and the modification of extracellular matrix (Figure 3). BMPRIA knockdown results in an increase in VEGF, TSP1 and ANGPT1 associated with angiogenesis. We also measured several markers associated with EMT and saw a downregulation of CDH1 (encodes for E-cadherin) and a significant upregulation of VIMENTIN, NES and the transcription factors SIP1 and SLUG. These changes suggest a change towards a more mesenchymal type of cell. No significant changes in the transcription factors ZEB1 and SNAI1 were observed. BMPRIA knockdown also resulted in the upregulation of the stem cell markers CD24 and EPCAM, but not in changes in CD44. The expression of matrix metalloproteinases 2 and 14 (MMPs) is also significantly increased after BMPRIA knockdown. These MMPs are involved in the breakdown of extracellular matrix and tissue remodelling, which is associated with tumour progression (Ellenrieder et al, 2000).

The overall results of changes in SMAD4 and BMPRIA expression are schematically presented in Figure 4.

The BMP pathway as a treatment target. We further investigated whether the BMP pathway could be used as a treatment target. We treated the three cell lines (PANC-1, MIA PaCa-2 and Bx-PC3) with BMP-2 and the BMPRIA inhibitor LDN-193189 for $48 \mathrm{~h}$ and investigated the effect on cell viability/proliferation. Treatment with $100 \mathrm{ng} \mathrm{ml}^{-1} \mathrm{BMP}-2$ resulted in a decrease in viability in the SMAD4-expressing cell lines PANC-1 and MIA $\mathrm{PaCa}-2$, but in an increase in the SMAD4-negative $\mathrm{Bx}-\mathrm{PC} 3$ (Figure 5A). We also treated the cells with different concentrations of the BMPRIA inhibitor LDN-193189 (Figure 5B). Up to $50 \mathrm{~nm}$ an increase in viability/proliferation can be seen in the SMAD4positive cells. A further increase in concentration results in a reduction in viability/proliferation, probably because of toxic effects. In Bx-PC3, a dose-dependent decrease in viability/ proliferation can be observed.

We repeated these experiments using the shSMAD4 PANC-1 cells and observed that BMP2 treatment of the SMAD4-expressing cells (shControl) results in a decrease in viability, but not in the shSMAD4 cells (Figure 5C). BMP inhibition results in a decrease in cell viability in the shSMAD4 cells but not in the shControl cells (Figure 5D). We conclude that the BMP signalling pathway can induce tumour promotion or suppression dependent on the SMAD4 status (Figure 5E).

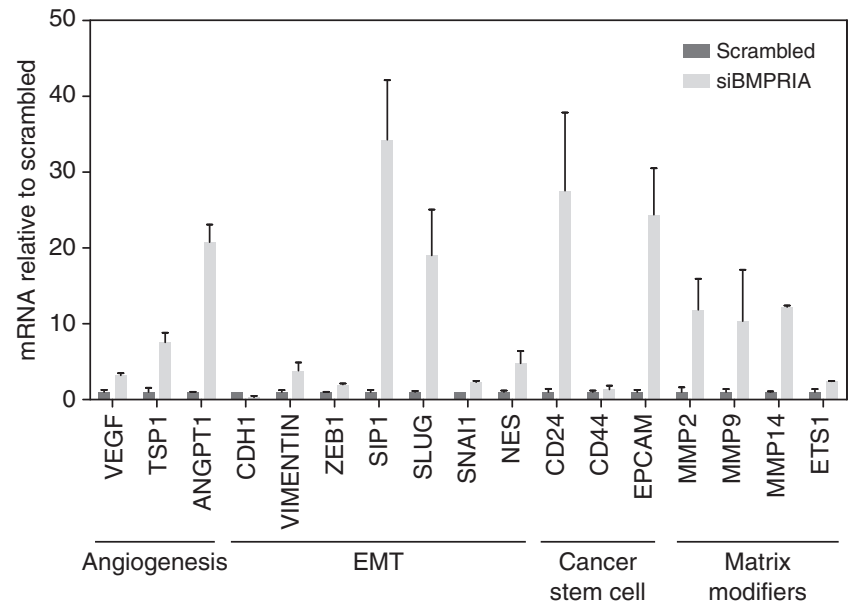

Figure 3. BMPRIA knockdown leads to an increase in markers associated with angiogenesis, EMT, cancer stemness and matrix modification in PANC-1 cells. A significant increase is seen in VEGF, TSP1, ANGPT1, VIMENTIN, SIP1, SLUG, NES, CD24, EPCAM, MMP2, MMP14 and ETS1.

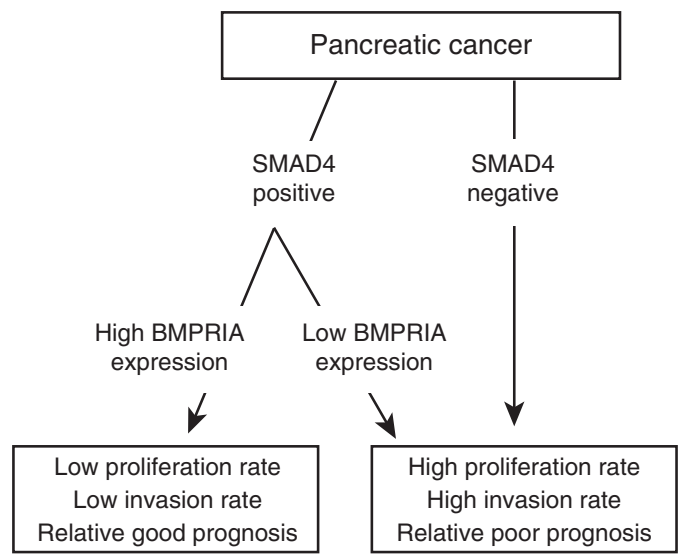

Figure 4. A scheme presenting the effects of SMAD4 and/or BMPRIA loss in PDAC.

\section{DISCUSSION}

We set out to investigate the expression levels of BMP signalling components in PDAC and link this to patient's survival data. We found that in $53.7 \%$ of the cases BMPRIA expression is reduced, and that this is associated with a poorer survival $(P=0.008)$. When we stratified for SMAD4 expression it could be observed that reduced BMPRIA expression only makes a difference in SMAD4-positive cancers. SMAD4 is necessary for the canonical BMP pathway and loss of SMAD4 results in a defect in canonical BMP signalling. Subsequent reduction of BMPRIA expression in SMAD4-negative cancer does not reduce the canonical BMP signalling activity further and probably has little additional impact. Reduction of either BMPRIB or BMPRII does not lead to a difference in survival and does not occur as frequently as loss of BMPRIA expression (9.8\% and $29.3 \%)$.

Reduction in the expression of one or more BMPRs has been found in several other tumour types. Aberrant BMPRII expression based on immunohistochemistry has been found in prostate 

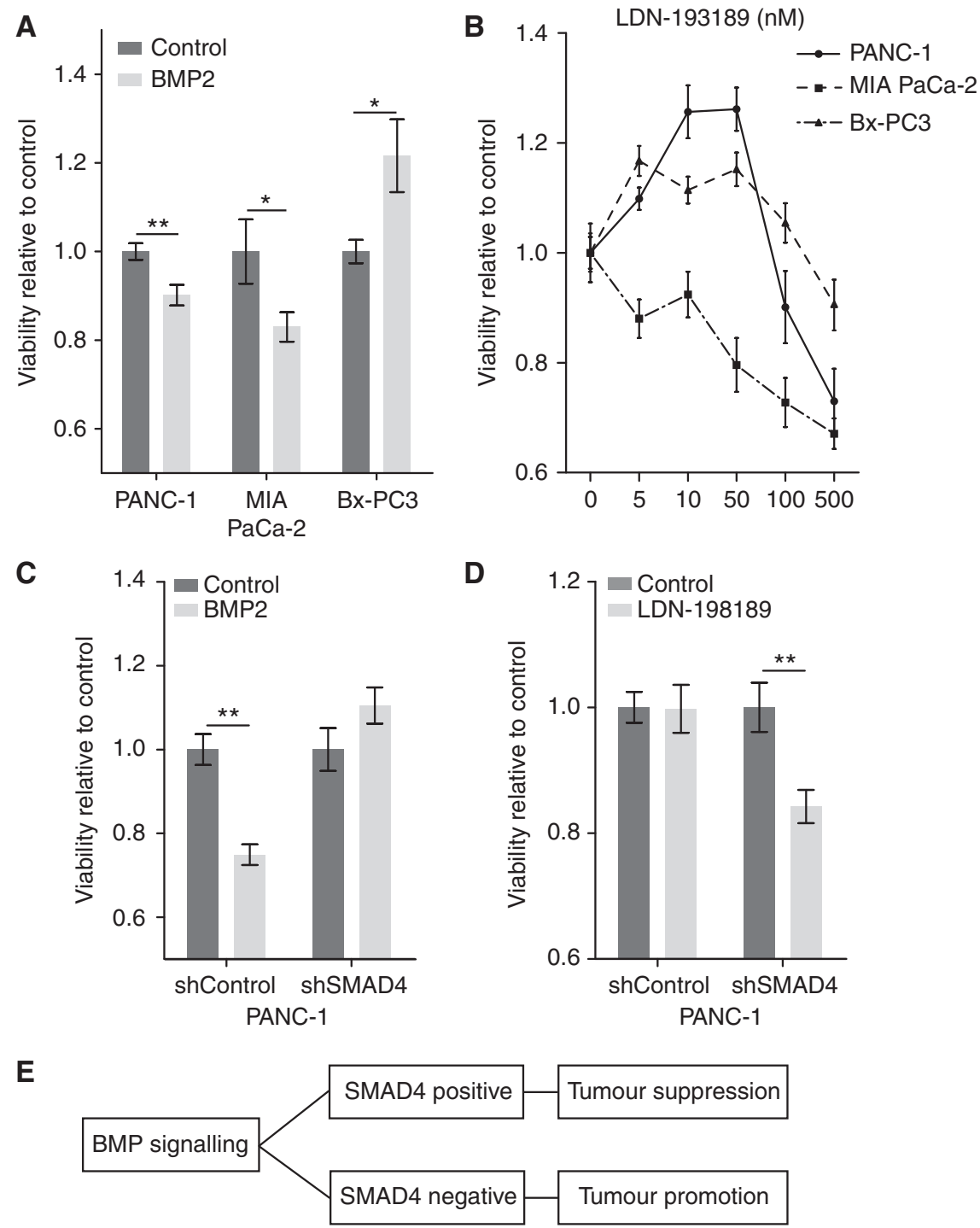

Figure 5. Treatment of (PDAC) cell lines PANC-1, MIA PaCa-2 and Bx-PC3 with BMP-2 and BMPR1 inhibitor LDN-193189. (A) PDAC cell lines were treated with $100 \mathrm{ng} \mathrm{ml}^{-1}$ of BMP-2 for $48 \mathrm{~h}$. Cell proliferation/viability was subsequently assessed using an MTT assay was performed. (B) PDAC cancer cell lines were treated with different concentrations of LDN-193189 for $48 \mathrm{~h}$. Subsequently an MTT assay was performed. (C and D) PANC-1 cells were transduced with either shRNA against SMAD4 or an empty control vector. The cell lines were treated with $100 \mathrm{ng} \mathrm{m}^{-1}$ of BMP-2 for $48 \mathrm{~h}$ or $5 \mathrm{nM}$ of LDN-193189 and proliferation/viability assessed using an MTT assay. The cell proliferation/viability is compared with the control condition, which is set to 1. (E) Proposed effect of BMP signalling based on SMAD4 status.

cancer (Kim et al, 2004) and in renal cell carcinomas (Kim et al, 2003). Our group has previously identified mutations in the $3^{\prime} \mathrm{UTR}$ of BMPRII in microsatellite instable colorectal cancer, which resulted in reduced expression levels (Kodach et al, 2008b). Although BMPRIA protein expression in PDAC has not previously been published, BMPRIA expression in PDAC has been assessed as part of the human protein atlas (www.proteinatlas.org) using a different antibody (CAB019398; Strategic Diagnostics Inc., Newark, DE, USA). This also showed absent BMPRIA expression in $56 \%$ of the cancers and strong expression in normal pancreatic tissue.

To further explore the effects of reduced BMPRIA expression in PDAC, we investigated three PDAC cell lines (PANC-1, MIA PaCA-2 and Bx-PC3). It has previously been published that BMPRIA is not expressed in MIA PaCa-2 cells at mRNA level using northern blot (Kleeff et al, 1999). We found that MIA PaCa-2 expresses lower levels of BMPRIA protein compared with PANC-1 and Bx-PC3, but equal levels of mRNA by RT-PCR using primers specific for exon 13. We found no PDAC cell lines with complete loss of BMPRIA. This is consistent with our immunohistochemistry staining results where we found that, although $53.7 \%$ had reduced expression levels of BMPRIA and were thereby regarded as 'negative' in our scoring system, only a small portion $(4.9 \%)$ of the PDAC had completely lost BMPRIA expression. The underlying reason for the reduced BMPRIA protein expression we observe remains unclear. Large-scale mutational studies of large cohorts of PDAC $(n=100)$ have not revealed mutations in BMPRIA (Biankin et al, 2012) and studies that specifically mention analysis of BMPRIA in pancreatic cancer have also not revealed mutations $(n=31$; Jones et al, 2008; Kan et al, 2010). Although none of these studies has focussed specifically on BMPRIA, it seems unlikely that mutations in the coding region of BMPRIA can explain the altered protein expression at the frequency that we observe. As MIA PaCa-2 seems to have normal mRNA levels in our analyses, but reduced protein levels, the cause will most likely be post-transcriptional such as miRNA inhibition of translation. For our protein expression studies using immunohistochemistry and immunoblotting, 
we used a polyclonal antibody raised against amino acids $24-83$ of BMPRIA as used by several other groups (Deng et al, 2007; Barros et al, 2008; Medici et al, 2010; Du et al, 2011). On immunoblots using this antibody, we detect a major band at the predicted height of around $60 \mathrm{kD}$ with other bands at approximately 50 and $45 \mathrm{kD}$ as shown in the antibody product datasheet and as also seen with polyclonal BMPRIA antibodies from other manufacturers (e.g., ab38560 from Abcam (Cambridge, UK)) in cell lysates of various origins. The specificity of these antibodies is confirmed by the virtual disappearance of all these bands when PANC-1 cells are treated with BMPRIA-specific siRNA (Figure 2E).

The reduction of BMPRIA expression in SMAD4-positive PDAC cells resulted in an increase in cell viability, matrigel invasion and the upregulation of several markers associated with angiogenesis, EMT, cancer stemness and matrix modification. These processes can lead to a more aggressive cancer. The markers were measured using qPCR only, and therefore the conclusions must be considered preliminary, but this might be the reason that reduced BMPRIA expression is associated with a poorer prognosis. These results have to be further confirmed at protein level and using functional assays.

Finally, we investigated the possibility of using BMP pathway modulation as a novel treatment. Treatment with BMP-2 results a decrease in viability in SMAD4-positive PDAC cells, but an increase in viability in SMAD4-negative cells. Treatment with LDN-193189, a small molecule BMPRI inhibitor, results in an increase in viability in SMAD4-positive cells, but a decrease in viability SMAD4-negative cells. It may be that BMP signalling has a dual role dependent on SMAD4 expression. It could be that when SMAD4 is present BMP acts as a tumour suppressor, whereas when SMAD4 is lost BMP acts as a tumour promoter. This phenomena, of a contradictory effect dependent on the expression status of a particular protein, has previously been reported in colorectal cancer with the TGF- $\beta$ signalling pathway and SMAD4 expression (Zhang et al, 2010) where the SMAD4 expression status determined the metastatic effects of TGF- $\beta$. A second example is the TGF- $\beta$ switch from anti-proliferative into pro-metastatic dependent on the p53 mutational status (Adorno et al, 2009). In the absence of SMAD4, BMPs cannot signal through the canonical SMAD4-dependent signalling route. That BMP ligands still have important biological effects in the absence of SMAD4, as we and others have shown, is evidence for important noncanonical SMAD4-independent signalling. There is not much data on non-canonical BMP signalling, but it is known that SMADindependent BMP signalling can activate p38MAPK, ERK and JNK in colorectal cancer (Grijelmo et al, 2007). p38, ERK and JNK are mitogen-activated protein kinases associated with tumour progression, which could explain the increase in viability observed after activating non-canonical BMP signalling.

This data would suggest that modulating the BMP pathway as part of a combined treatment strategy, as has been suggested in other cancers, will have to be targeted to specific tumours based on their SMAD4 expression status. Theoretically, BMP treatment could be used for SMAD4-positive cancers and BMPRIA inhibitors might be possible candidates for treatment of SMAD4 mutated PDACs, analogous to the use of TGF- $\beta$ RIA inhibitors (Ge et al, 2006).

Although activation or inhibition of the same pathway for treatment of the same cancer type is perhaps conceptually confusing, at the very least these data would suggest caution in treating PDAC with BMP-modulating agents as they may potentially have adverse effects. The tumour stroma has a major role in the development and progression of PDAC, also affecting cancer therapy. In these studies, we have made use of well validated and frequently used in vitro models consisting of the tumour epithelial cells only. Further research in more complex in vitro and in vivo models will be needed to investigate the effects of BMP manipulation on stromal cells and their interaction with cancer cells.

In summary, we have studied the expression levels of BMPRs in PDAC tissue based on immunohistochemistry and linked this to patient's survival data. We show that a reduction in the expression of BMPRIA is associated with a poorer prognosis. Stratifying for SMAD4 reveals that this is mainly in a sub-population of SMAD4positive cancers. BMPRIA expression might be useful as a prognostic bio-marker, especially when combined with SMAD4. By manipulating BMPRIA in vitro, we show that BMPRIA has tumour-suppressive effects, which are dependent on the SMAD4 status. The small molecule BMPRIA inhibitor LDN-193189 has antitumour activity in SMAD4-negative PDAC cells.

\section{ACKNOWLEDGEMENTS}

We thank JT van Wezel for help with collecting the tissue, $\mathrm{P}$ ten Dijke for providing BRE-luc and CAGA-luc expression vectors and LJ Hawinkels and M Paauwe for providing the MMP RT-PCR primers. PWV and JCHH are funded by the Netherlands Digestive Diseases Foundation. LLK is funded by the Dutch Cancer Foundation (KWF, UL 2011-5089).

\section{CONFLICT OF INTEREST}

The authors declare no conflict of interest.

ETHICS APPROVAL

The study was approved by the investigator's institutional review board.

\section{AUTHOR CONTRIBUTIONS}

PWV: designed and performed experiments, analysed data, wrote manuscript; VS, RJJ, ES, AIS, AL, KSK and SML: performed experiments; NFCCDM and HM: provided tissue and patient data; LLK: designed experiments, analysed data, supervised project; JCHH: designed experiments, analysed data, wrote manuscript, supervised project.

\section{REFERENCES}

Adorno M, Cordenonsi M, Montagner M, Dupont S, Wong C, Hann B, Solari A, Bobisse S, Rondina MB, Guzzardo V, Parenti AR, Rosato A, Bicciato S, Balmain A, Piccolo S (2009) A mutant-p53/Smad complex opposes p63 to empower TGFbeta-induced metastasis. Cell 137(1): 87-98. Barros R, Pereira B, Duluc I, Azevedo M, Mendes N, Camilo V, Jacobs RJ, Paulo P, Santos-Silva F, van Seuningen I, van den Brink GR, David L, Freund JN, Almeida R (2008) Key elements of the BMP/SMAD pathway co-localize with CDX2 in intestinal metaplasia and regulate CDX2 expression in human gastric cell lines. J Pathol 215(4): 411-420.

Biankin AV, Waddell N, Kassahn KS, Gingras MC, Muthuswamy LB, Johns AL, Miller DK, Wilson PJ, Patch AM, Wu J, Chang DK, Cowley MJ, Gardiner BB, Song S, Harliwong I, Idrisoglu S, Nourse C, Nourbakhsh E, Manning S, Wani S, Gongora M, Pajic M, Scarlett CJ, Gill AJ, Pinho AV, Rooman I, Anderson M, Holmes O, Leonard C, Taylor D, Wood S, Xu Q, Nones K, Fink JL, Christ A, Bruxner T, Cloonan N, Kolle G, Newell F, Pinese M, Mead RS, Humphris JL, Kaplan W, Jones MD, Colvin EK, Nagrial AM, Humphrey ES, Chou A, Chin VT, Chantrill LA, Mawson A, Samra JS, Kench JG, Lovell JA, Daly RJ, Merrett ND, Toon C, Epari K, Nguyen NQ, Barbour A, Zeps N, Kakkar N, Zhao F, Wu YQ, Wang M, Muzny DM, Fisher WE, Brunicardi FC, Hodges SE, Reid JG, Drummond J, 
Chang K, Han Y, Lewis LR, Dinh H, Buhay CJ, Beck T, Timms L, Sam M, Begley K, Brown A, Pai D, Panchal A, Buchner N, De BR, Denroche RE, Yung CK, Serra S, Onetto N, Mukhopadhyay D, Tsao MS, Shaw PA, Petersen GM, Gallinger S, Hruban RH, Maitra A, Iacobuzio-Donahue CA, Schulick RD, Wolfgang CL, Morgan RA, Lawlor RT, Capelli P, Corbo V, Scardoni M, Tortora G, Tempero MA, Mann KM, Jenkins NA,

Perez-Mancera PA, Adams DJ, Largaespada DA, Wessels LF, Rust AG, Stein LD, Tuveson DA, Copeland NG, Musgrove EA, Scarpa A, Eshleman JR, Hudson TJ, Sutherland RL, Wheeler DA, Pearson JV, McPherson JD, Gibbs RA, Grimmond SM (2012) Pancreatic cancer genomes reveal aberrations in axon guidance pathway genes. Nature 491(7424): 399-405.

Carlotti F, Bazuine M, Kekarainen T, Seppen J, Pognonec P, Maassen JA, Hoeben RC (2004) Lentiviral vectors efficiently transduce quiescent mature 3T3-L1 adipocytes. Mol Ther 9(2): 209-217.

Deng H, Makizumi R, Ravikumar TS, Dong H, Yang W, Yang WL (2007) Bone morphogenetic protein- 4 is overexpressed in colonic adenocarcinomas and promotes migration and invasion of HCT116 cells. Exp Cell Res 313(5): 1033-1044.

Du J, Chen X, Liang X, Zhang G, Xu J, He L, Zhan Q, Feng XQ, Chien S, Yang C (2011) Integrin activation and internalization on soft ECM as a mechanism of induction of stem cell differentiation by ECM elasticity. Proc Natl Acad Sci USA 108(23): 9466-9471.

Duda DG, Sunamura M, Lefter LP, Furukawa T, Yokoyama T, Yatsuoka T, Abe T, Inoue H, Motoi F, Egawa S, Matsuno S, Horii A (2003) Restoration of SMAD4 by gene therapy reverses the invasive phenotype in pancreatic adenocarcinoma cells. Oncogene 22(44): 6857-6864.

Ellenrieder V, Alber B, Lacher U, Hendler SF, Menke A, Boeck W, Wagner M, Wilda M, Friess H, Buchler M, Adler G, Gress TM (2000) Role of MT-MMPs and MMP-2 in pancreatic cancer progression. Int J Cancer 85(1): 14-20.

Ge R, Rajeev V, Ray P, Lattime E, Rittling S, Medicherla S, Protter A, Murphy A, Chakravarty J, Dugar S, Schreiner G, Barnard N, Reiss M (2006) Inhibition of growth and metastasis of mouse mammary carcinoma by selective inhibitor of transforming growth factor-beta type I receptor kinase in vivo. Clin Cancer Res 12(14 Pt 1): 4315-4330.

Grijelmo C, Rodrigue C, Svrcek M, Bruyneel E, Hendrix A, De WO, Gespach C (2007) Proinvasive activity of BMP-7 through SMAD4/src-independent and ERK/Rac/JNK-dependent signaling pathways in colon cancer cells. Cell Signal 19(8): 1722-1732.

Hahn SA, Schutte M, Hoque AT, Moskaluk CA, da Costa LT, Rozenblum E, Weinstein CL, Fischer A, Yeo CJ, Hruban RH, Kern SE (1996) DPC4, a candidate tumor suppressor gene at human chromosome 18q21.1. Science 271(5247): 350-353.

Hansel DE, Kern SE, Hruban RH (2003) Molecular pathogenesis of pancreatic cancer. Annu Rev Genomics Hum Genet 4: 237-256.

Howe JR, Bair JL, Sayed MG, Anderson ME, Mitros FA, Petersen GM, Velculescu VE, Traverso G, Vogelstein B (2001) Germline mutations of the gene encoding bone morphogenetic protein receptor $1 \mathrm{~A}$ in juvenile polyposis. Nat Genet 28(2): 184-187.

Howe JR, Roth S, Ringold JC, Summers RW, Jarvinen HJ, Sistonen P, Tomlinson IP, Houlston RS, Bevan S, Mitros FA, Stone EM, Aaltonen LA (1998) Mutations in the SMAD4/DPC4 gene in juvenile polyposis. Science 280(5366): 1086-1088.

Jazag A, Ijichi H, Kanai F, Imamura T, Guleng B, Ohta M, Imamura J, Tanaka Y, Tateishi K, Ikenoue T, Kawakami T, Arakawa Y, Miyagishi M, Taira K, Kawabe T, Omata M (2005) Smad4 silencing in pancreatic cancer cell lines using stable RNA interference and gene expression profiles induced by transforming growth factor-beta. Oncogene 24(4): 662-671.

Jemal A, Bray F, Center MM, Ferlay J, Ward E, Forman D (2011) Global cancer statistics. CA Cancer J Clin 61(2): 69-90.

Jones S, Zhang X, Parsons DW, Lin JC, Leary RJ, Angenendt P, Mankoo P, Carter H, Kamiyama H, Jimeno A, Hong SM, Fu B, Lin MT, Calhoun ES, Kamiyama M, Walter K, Nikolskaya T, Nikolsky Y, Hartigan J, Smith DR, Hidalgo M, Leach SD, Klein AP, Jaffee EM, Goggins M, Maitra A, Iacobuzio-Donahue C, Eshleman JR, Kern SE, Hruban RH, Karchin R, Papadopoulos N, Parmigiani G, Vogelstein B, Velculescu VE, Kinzler KW (2008) Core signaling pathways in human pancreatic cancers revealed by global genomic analyses. Science 321(5897): 1801-1806.
Kan Z, Jaiswal BS, Stinson J, Janakiraman V, Bhatt D, Stern HM, Yue P, Haverty PM, Bourgon R, Zheng J, Moorhead M, Chaudhuri S, Tomsho LP, Peters BA, Pujara K, Cordes S, Davis DP, Carlton VE, Yuan W, Li L, Wang W, Eigenbrot C, Kaminker JS, Eberhard DA, Waring P, Schuster SC, Modrusan Z, Zhang Z, Stokoe D, de Sauvage FJ, Faham M, Seshagiri S (2010) Diverse somatic mutation patterns and pathway alterations in human cancers. Nature 466(7308): 869-873.

Kim IY, Lee DH, Lee DK, Ahn HJ, Kim MM, Kim SJ, Morton RA (2004) Loss of expression of bone morphogenetic protein receptor type II in human prostate cancer cells. Oncogene 23(46): 7651-7659.

Kim IY, Lee DH, Lee DK, Kim BC, Kim HT, Leach FS, Linehan WM, Morton RA, Kim SJ (2003) Decreased expression of bone morphogenetic protein (BMP) receptor type II correlates with insensitivity to BMP-6 in human renal cell carcinoma cells. Clin Cancer Res 9(16 Pt 1): 6046-6051.

Kleeff J, Maruyama H, Ishiwata T, Sawhney H, Friess H, Buchler MW, Korc M (1999) Bone morphogenetic protein 2 exerts diverse effects on cell growth in vitro and is expressed in human pancreatic cancer in vivo. Gastroenterology 116(5): 1202-1216.

Kodach LL, Bleuming SA, Musler AR, Peppelenbosch MP, Hommes DW, van den Brink GR, van Noesel CJ, Offerhaus GJ, Hardwick JC (2008a) The bone morphogenetic protein pathway is active in human colon adenomas and inactivated in colorectal cancer. Cancer 112(2): 300-306.

Kodach LL, Wiercinska E, De Miranda NF, Bleuming SA, Musler AR, Peppelenbosch MP, Dekker E, van den Brink GR, van Noesel CJ, Morreau H, Hommes DW, Ten DP, Offerhaus GJ, Hardwick JC (2008b) The bone morphogenetic protein pathway is inactivated in the majority of sporadic colorectal cancers. Gastroenterology 134(5): 1332-1341.

Korchynskyi O, Ten DP (2002) Identification and functional characterization of distinct critically important bone morphogenetic protein-specific response elements in the Id1 promoter. J Biol Chem 277(7): 4883-4891.

Massague J (1998) TGF-beta signal transduction. Annu Rev Biochem 67: 753-791.

Massague J, Blain SW, Lo RS (2000) TGFbeta signaling in growth control, cancer, and heritable disorders. Cell 103(2): 295-309.

Medici D, Shore EM, Lounev VY, Kaplan FS, Kalluri R, Olsen BR (2010) Conversion of vascular endothelial cells into multipotent stem-like cells. Nat Med 16(12): 1400-1406.

Romero D, Iglesias M, Vary CP, Quintanilla M (2008) Functional blockade of Smad4 leads to a decrease in beta-catenin levels and signaling activity in human pancreatic carcinoma cells. Carcinogenesis 29(5): 1070-1076.

Rozenblum E, Schutte M, Goggins M, Hahn SA, Panzer S, Zahurak M, Goodman SN, Sohn TA, Hruban RH, Yeo CJ, Kern SE (1997) Tumorsuppressive pathways in pancreatic carcinoma. Cancer Res 57(9): 1731-1734.

Schniewind B, Groth S, Sebens MS, Sipos B, Schafer H, Kalthoff H, Fandrich F, Ungefroren H (2007) Dissecting the role of TGF-beta type I receptor/ALK5 in pancreatic ductal adenocarcinoma: Smad activation is crucial for both the tumor suppressive and prometastatic function. Oncogene 26(33): $4850-4862$.

Tascilar M, Skinner HG, Rosty C, Sohn T, Wilentz RE, Offerhaus GJ, Adsay V, Abrams RA, Cameron JL, Kern SE, Yeo CJ, Hruban RH, Goggins M (2001) The SMAD4 protein and prognosis of pancreatic ductal adenocarcinoma. Clin Cancer Res 7(12): 4115-4121.

Vincent A, Herman J, Schulick R, Hruban RH, Goggins M (2011) Pancreatic cancer. Lancet 378(9791): 607-620.

Wilentz RE, Iacobuzio-Donahue CA, Argani P, McCarthy DM, Parsons JL, Yeo CJ, Kern SE, Hruban RH (2000) Loss of expression of Dpc4 in pancreatic intraepithelial neoplasia: evidence that DPC4 inactivation occurs late in neoplastic progression. Cancer Res 60(7): 2002-2006.

Zhang B, Halder SK, Kashikar ND, Cho YJ, Datta A, Gorden DL, Datta PK (2010) Antimetastatic role of Smad4 signaling in colorectal cancer. Gastroenterology 138(3): 969-980.

This work is published under the standard license to publish agreement. After 12 months the work will become freely available and the license terms will switch to a Creative Commons AttributionNonCommercial-Share Alike 3.0 Unported License.

Supplementary Information accompanies this paper on British Journal of Cancer website (http://www.nature.com/bjc) 